\title{
Effects of Perceptual Learning Styles and Learning Strategies on College Students' Spoken English Proficiency
}

\author{
Shenghua Chu \\ School of Foreign Languages of Yanshan University \\ Qin Huangdao, the People's Republic of China \\ E-mail: 1loydtrue@163.com
}

\begin{abstract}
With the advancements of the studies of second language acquisition, learning styles have been put as the center of relevant studies. However, studies on the mechanism of how perceptual learning styles influence non-English major students' spoken English proficiency have been unsubstantial, needing further exploration. The present paper is undertaken to investigate the frequency of perceptual learning styles of non-English majors and their spoken English proficiency, in order to explore the mechanism in which perceptual learning styles influence learners' spoken English proficiency. The study adopted quantitative and qualitative methods to collect and analyze the relevant information. The result of the study indicated that perceptual learning styles indirectly influence learners' spoken English proficiency by directly influencing learners' choice and employment of learning strategies. The findings of the study are significant in helping English teachers promote non-English major students' spoken English proficiency by adjusting and accommodating their perceptual learning styles to their individualities.
\end{abstract}

Keywords-learning styles; learning strategies; spoken English proficiency

\section{INTRODUCTION}

From the 1970s, experts in English pedagogy came to focus on the influence of learners' individual differences on their academic achievement. It is universally believed that learners' individual characteristics do exert great impact on learners' language achievement. Learning styles, as the main part of learners' individual factors, have been put as the center of relevant studies. Foreign scholars conducted a large quantity of empirical studies, which mainly explored the interrelationships between learning styles, learning strategies and language achievements, such as reading, listening, writing and vocabulary. Compared with the studies abroad, relevant studies started much later in China, concentrating mainly on the introduction of relevant theories imported from abroad. Empirical studies are rarely found in China. In addition, studies on the subcategory of perceptual learning styles have been unsubstantial, especially how perceptual learning styles influence learners' spoken English proficiency needs further exploration.

The present paper is undertaken to investigate the frequency of perceptual learning styles and learning strategies of non-English majors and their spoken English proficiency, aiming to explore the puzzle of how perceptual learning styles and learning strategies influence learners' spoken English proficiency.

\section{METHODOLOGY}

\section{A. Theoretical Framework of the Study}

The theoretical framework on which the present study is based is adapted from the framework for investigating individual learner differences set up by Ellis [1]. Ellis pointed out that individual differences did exist among various learners in both the way they set about learning a second language and in where they actually succeed in learning. He identified three sets of interrelating variables: the first set consists of individual differences: beliefs about language learning, affective states and general factors. General factors include age, language aptitude, learning styles, motivation and personality. The second set of variables consists of the different strategies that a learner employs to learn and use the L2. The third set consists of language learning outcomes. The inner part of the triangle is hidden learning processes and mechanisms. The three sets of factors interrelated in complex ways, as is shown in Figure 1 which was composed by the author of the study.

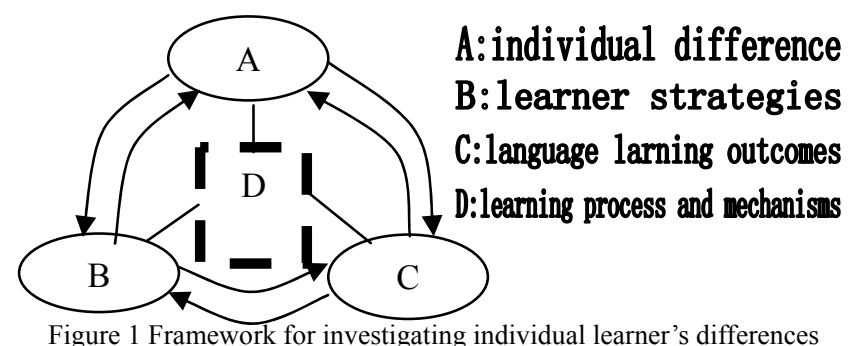

\section{B. Research Questions}

The current study is mainly to explore how the perceptual learning styles and learning strategies influence spoken English proficiency of non-English major students in Yanshan University with an effort to answer the following research questions:1) What are the distributions of perceptual learning styles and learning strategies employed by the non-English major college students? 2) What are the relationships among learning styles, learning strategies and spoken English proficiency?

The perceptual learning styles examined in this study are: visual preference, auditory preference, tactile preference, kinesthetic preference, group preference and individual preference. While the learning strategies are: direct strategies (memory strategies, cognitive strategies, and compensation strategies) and indirect strategies (meta-cognitive strategies, affective strategies and social strategies). 


\section{Subjects of the Study}

The subjects of the study are 174 non-English sophomore students in Yanshan University, coming from the college of Information Science and Engineering, College of Science, and College of Economics and Management. All the subjects have passed CET-4 in December 2010 with comparatively similar scores, the discrete degree being permissible. The conditions of the subjects guarantee the relevant variables under control, thus making the subjects of the presents study suitable.

\section{Instruments}

In this study, three measuring instruments are employed: Perceptual Learning Style Preference Questionnaire (PLSPQ) adapted from Reid [2]; Strategy Inventory for Language Learning (SILL) by Oxford [3]; a standardized spoken English proficiency test. The first two instruments are to find out the distributions of subjects' learning styles and learning strategies; the third instrument is to find out subjects' spoken English proficiency.

\section{Questionnaires}

Perceptual Learning Styles Preference Questionnaire (PLSPQ) begins with the subjects' personal information such as name, gender, age, discipline and CET-4 score. The next part is the directions and examples to help the subjects correctly finish all the items of the questionnaire. Based on the instructions of PLSPQ, the final scores of each styles between 38 and 50 are major learning style preferences, that between 25 to 37 are the minor learning style preference and that between 0 and 24 can be negligible.

Strategy Inventory for Language Learning (SILL) (for non-native speakers) examines six language learning strategies through 50 statements that are on a 5-scale continuum. The higher score a subject gets, the more frequently he uses learning strategies. The frequency of learners' learning strategies could be defined into three levels: the average score ranging between 3.5 and 5.0 are of high frequency; that between 2.5 and 3.4 are of medium frequency; and that between 1.0 and 2.4 are of low frequency.

\section{Standardized Spoken English Proficiency Test}

The third instrument is the standardized Spoken English Proficiency Test (SEPT) conducted by the author and his nine colleagues, including six foreign teachers (English speakers) in Yanshan University. This SEPT emphasized the communicative competence: grammar competence, sociolinguistic competence, context competence and strategic competence. In the first part of SEPT every subject was given a topic to talk about for 2 minutes, the aim being to examine subjects' linguistic competence. The second section was a role-play, with every two subjects being put into a specific social-communicative occasion to fulfill a communicative task. The competence examined is pragmatic competence. The last section was for subjects to describe a series of four interrelated pictures that constitute a short story. This section mainly focused on subjects' information transmission competence. The Cronbach alpha coefficient of the reliability of the test is 0.78 , indicating SEPT is highly reliable.

\section{E. Data Collection Procedure}

The present study was conducted in March 2011. PLSPQ and SILL were respectively administered to the subjects during class time, each lasting about 35 minutes. Altogether 186 questionnaires were distributed with 185 being collected back. Among which, 7 were mistakenly answered and 4 were incomplete, thus they were disused. Then the effective questionnaires were 174 and subjects were thus selected. From March 24 to April 18, the SEPT was launched to test all the 174 subjects' spoken English proficiency. The performances of subjects' SEPT were transcribed and then examined.

\section{F. Data Analysis}

The present study adopted quantitative analysis. First, the results of the questionnaires were fed into computer to be processed by SPSS for quantitative analysis to analyze the distributions of learning strategies and perceptual learning styles, and still the correlations among perceptual learning styles, learning strategies and spoken English proficiency.

\section{RESULTS AND DISCUSSIONS}

\section{A. Frequency and Distributions of Overall Learning Strategies}

According to the SILL, the score of overall learning strategies can indicate how often students employ language learning strategies when learning. The results of the SILL demonstrate that $59.3 \%$ of the subjects sometimes use learning strategies and nearly one quarter generally do not use learning strategies often, while only $14.9 \%$ of the subjects usually use learning strategies. At both two extremes, $1.1 \%$ subjects always use learning strategies and $2.3 \%$ never. The results indicate a low percentage of subjects' using learning strategies.

The frequency of overall learning strategies serves only to describe the subjects' use of learning strategies on a macro-level, which cannot specifically offer precise information as to which subtypes of learning strategies are preferred most and which least. Then the present study tries to give a detailed descriptive account of the six subcategories of learning strategies adopted by the subjects. The mean of metacognitive strategies (mean=3.6452) ranks the highest position among the six learning strategies, while compensation strategies occupy the lowest (mean=2.3466), which means that metacognitive strategies are most preferred by subjects and compensation strategies are the least frequently used. The sequence of the utilization of learning strategies (from the most frequently used to the least) by all the subjects is metacognitive strategies, social strategies, affective strategies, cognitive strategies, memory strategies and compensation strategies.

The metacognitive strategies employed by subjects can make use of knowledge about cognitive processes and constitute an attempt to regulate language learning by means of planning, monitoring, and evaluating. As in [1] metacognitive strategies are more evident in adult learners, which is in accordance with the result of this study, that is students most frequently employ metacognitive strategies consciously to monitor their learning process. Students are now aware of the importance to them to coordinate their learning activities, so they consciously use metacognitive strategies to make study plans, to get self-monitored and self-evaluated. 
Affective strategies follow next as the second preferred learning strategies. Affective strategies are the ways in which learners deal with their affectional and emotional states when learning. As college adult students, the subjects in the present study are mature in their psychology and emotion so that they can consciously or unconsciously activate their emotion regulation devices to lower their anxiety, get encouraged and take their emotional temperature to facilitate the process of learning.

Cognitive strategies possessed the third place among the six with the mean score 2.9417. Cognitive strategies are very important when learners learn a new language. Cognitive strategies vary from repeating to analyzing expressions to summarizing. With all the varieties, cognitive strategies are unified by a common function: manipulation or transformation of the target language, as in [3]. Practicing is the most important cognitive strategies, which include repeating---saying or doing something over and over. As college English learners, the subjects have to recite the new words frequently, some of them get up early in the morning reading English materials. In addition, teachers often encourage students to read or recite passages, which may be a contributor to the subjects' preference of cognitive strategies.

Memory strategies are not so welcome among the subjects $($ mean $=2.7704)$, followed by social strategies $($ mean $=2.4782)$ and compensation strategies (mean=2.3466). It means that college students do not often apply memory strategies to their language learning. Reference [3] listed the memory skills: connecting the sound of a new word and an image or picture of the word; connecting new word with the word learnt; using rhymes to help to memorize new words. Different from senior middle school students, college students don't have the pressure to pass College Entrance Examination which requires much memorization. Furthermore, in college skillful application of a language is highlighted, so they focus more on how to put them into practice, instead of bothering to remember those fixed rules and lifeless words. These factors may result in the low preference of memory strategies. The result is in accordance with Oxford and Nyikos [4], they stated that although memory strategies can be powerful contributors to language learning, university students report using memory strategies infrequently.

As a form of social behaviors, language is about communication, which involves people's participation. Then learning a language also involves other people, and appropriate social strategies are very important in the process, as in [3]. Social strategies include asking questions, cooperating with others as well as empathy, which can help all learners increase their ability to emphasize by developing cultural understanding and becoming aware of other's thoughts and feelings, as in [3]. But in the present study, social strategies are the second least preferred learning strategies among subjects. The reason of this result may have something to do with Chinese current college English teaching practice. From 1998, large numbers of high school graduates were admitted into colleges while the physical and teaching facilities in most of the universities haven't been "updated" simultaneously. This led to many more students sitting in one classroom to study English, which makes it almost impossible for teachers to conduct any activity that is essential in learning a language. There is no interaction between teachers and students, and even among students themselves.

The surprising result is that compensation strategies are least frequently used by the subjects (mean=2.3466). Compensation strategies enable learners to use the new language for either comprehension or production despite limitations in knowledge. Reference [3] believed compensation strategies are intended to make up for an inadequate repertoire of grammar and, especially, of vocabulary. Two sets are included in compensation strategies: guessing intelligently in listening and reading, overcoming limitations in speaking and writing.

Based on the later interview, the author concluded that there are two reasons for this phenomenon. The first one is that most of the students never get trained on learning strategies, some even have never heard of such terminologies, not to mention the knowledge of how to apply learning strategies to their language studies. Secondly, even those who know something about learning strategies do not realize their importance to them, so they never take them as a part of learning process.

\section{B. Distributions of Subjects' Perceptual Learning Styles}

The analysis of subjects' perceptual learning styles shows that tactile is the most preferred perceptual learning style among the six categories with the mean 39.27, kinesthetic following next (mean=38.09). On the contrary, the least preferred are individual $($ mean $=33.83)$ and group style $($ mean $=31.20)$. While auditory $($ mean $=36.63)$ and visual $($ mean $=34.79)$ styles rank in the middle position.

Tactile and kinesthetic styles, being the most favored learning styles, indicate that students could learn best by experience, by being involved physically in classroom experiences. They remember information well when they actively participate in activities, field trips, and role-plays in the classroom. Because these two styles allow learners to experience language totally, ESL learners prefer those most.

Visual and auditory styles are also preferred by subjects with means of 34.79 and 36.63 respectively. Visual learners learn well from seeing words in books, on the chalkboards and in workbooks. They remember and understand information and instructions better if they read them. While for auditory learners, they mainly learn from hearing works spoken and from oral explanation. They may remember information by reading aloud or moving their lips as they read, especially when they are learning new materials. They benefit from hearing audiotapes, lectures and classroom discussions. Teaching others and conversing with others could also enhance their study.

Individual and group styles are the least preferred by the subjects. Individual learners learn best when they work alone, think well when they think alone and remember best when they learn alone; while group learners learn best when learning through cooperation, working for the common benefits. In a group, they can support each other, not elevating above others. This may due to the collectivism of Chinese Confucian culture.

\section{Relationships Between Perceptual Learning Styles and Language Learning Strategies}

The correlation analysis shows that there do exist relationships between perceptual learning styles and 
language learning strategies, which indicates learning styles in some sense reflect the choice and use of learning strategies. Visual style has correlation with cognitive strategies (sig. $=0.004)$, affective strategies $($ sig. $=0.005)$, memory strategies (sig. $=0.015)$ and compensation strategies (sig. $=0.022$ ), while bearing no relationships with other two learning strategies. Auditory style has correlations with compensation strategies (sig. $=0.002)$, metacognitive strategies (sig. $=0.013)$ and social strategies $($ sig. $=0.024)$. Kinesthetic style has correlations with affective strategies (sig. $=0.001)$, memory strategies $($ sig. $=0.015)$, cognitive strategies $($ sig. $=0.019)$, metacognitive strategies $($ sig. $=0.024)$ and social strategies (sig. $=0.011)$. Tactile style has correlations with compensation strategies (sig. $=0.007)$ and affective strategies (sig. $=0.017$ ). Group style has correlations with memory strategies (sig. $=0.001)$, affective strategies (sig. $=0.003)$, cognitive strategies $($ sig. $=0.012)$, metacognitive strategies (sig. $=0.020)$. As to the individual style, it has correlations with only cognitive strategies (sig. $=0.019$ ). The analysis indicates that there are significant correlations between perceptual learning styles and language learning strategies. This conclusion is in line with many scholars' statements. Oxford [5] stated that "students' strategies are linked to their learning styles"; Rossi-Le [6] also commented that "an individual's learning style preference influences the types of learning strategies that he or she will employ in acquiring a second language".

\section{Relationships Between Perceptual Learning Styles and Spoken English Proficiency}

The spoken English proficiency of the subjects is quantified into scores which range from 0 to 100 . The main aspects measured in the SEPT are linguistic competence (pronunciation, fluency, grammar, language, vocabulary, conversation manipulation, and sentence processing), pragmatic competence (turn-taking, politeness principle, communicative strategies) and information transmission competence. The three aspects were given different weight when calculating the final score of each subject. The formula is: Total score $=$ linguistic competence $* 30 \%+$ pragmatic competence $* 40 \%+$ information transmission competence $* 30 \%$.

The result of SEPT indicates that the overall spoken English proficiency (mean=59.46) of students in Yanshan University is not very high. Female students are a little bit more proficient (mean=62.80) than male students $(\mathrm{mean}=57.99)$. This reflects that more work is needed to improve students' spoken English.

Another correlation analysis was made between the perceptual learning styles and Spoken English Proficiency. The analysis indicates that perceptual learning styles have no correlations with spoken English proficiency except group styles (sig. $=0.021$ ) and individual styles (sig. $=0.024)$. Group styles correlate positively with spoken English proficiency, while individual styles do negatively. It means that students may have a high level of proficiency in spoken English if they have stronger group styles or weaker individual styles. The probable explanation may be that students with group learning styles enjoy studying with others, and they will be more successful completing work well when working with others. Students with group styles tend to create and seek such opportunities to practice with others, thus their spoken English proficiency would certainly get bettered. On the other hand, students with individual styles prefer to study alone. They think better when they are alone, remember new information better when alone and they make better progress in learning when they work by themselves. Their learning styles conflict with the requisite of spoken language. The more alone they are, the less likelihood they have to practice a language. Thus, that they are not as proficient as those with group styles is well understandable.

In order to further explore the relationships between perceptual learning styles and spoken English proficiency, the author chose one group of thirty high proficient subjects (score $\geq 76.5$ ) and another group of thirty low proficient subjects (score $\leq 62.0)$ to find out if there is difference in learning styles between the two groups by using Independent Samples T-test. The result shows that among six perceptual learning styles only group styles correlate positively with students' spoken English proficiency with sig. $=0.022$. While individual styles negatively correlate with their spoken English proficiency with sig. $=0.023$. The overall analysis of relationships in the present study is mostly in accordance with other studies, which concluded that learning styles do not affect learners' L2 achievement directly. Reid [7] confirmed that proficiency level is not related with learning style preference.

\section{E. Relationships Between Language Learning Strategies and Spoken English Proficiency}

The correlation analysis between language learning strategies and spoken English proficiency clearly shows that except memory strategies, all the other five strategies significantly correlate with subjects' spoken English proficiency. Metacognitive strategies (sig. $=0.004$ ), affective strategies (sig. $=0.002)$, social strategies $\quad($ sig. $=0.001)$ significantly correlate with spoken English proficiency at the 0.01 level; and cognitive strategies (sig.=0.010) and compensation strategies $($ sig. $=0.021)$ significantly correlate at the 0.05 level. The result shows that learning strategies have relationships with $\mathrm{L} 2$ achievement.

In order to have a detailed analysis of the relationships between learning strategies and spoken English proficiency, another two sub-studies were carried out. The first study mainly focused on the effects of the choice and use of learning strategies on subjects' spoken English proficiency. In this study, the differences in subjects' spoken English proficiency between the subjects who employed language learning strategies frequently and those less frequently are examined. Two groups of sixty subjects were selected based on their PLSPQ questionnaire results, with one group subjects being frequent-use group, another being less-frequent-use group. Independent Samples T-test was employed to analyze the differences in spoken English proficiency between the two groups. The detailed results are as follows: the means of spoken English proficiency of frequent-use subjects are higher than those of less-frequent-use subjects, which indicates that subjects who use language learning strategies more frequently have higher proficiency in spoken English than those who use language learning strategies less frequently. Thus the choice and use of language learning strategies directly influence students' spoken English proficiency. Among the six language learning strategies, most of them make differences in spoken English proficiency between frequent and less-frequent users. For example, the choice and use of compensation strategies (sig. $=0.001)$, affective strategies (sig. $=0.003$ ), and social strategies (sig. $=0.001)$ significantly make differences in 
spoken English proficiency of the two groups at the 0.01 level; while cognitive strategies (sig. $=0.021)$ and metacognitive strategies (sig. $=0.019)$ significantly make differences at the 0.05 level. Only memory strategies ( $\operatorname{sig} .=0.296)$ make no difference. The result indicates that the more a learner use cognitive, metacognitive, compensation, affective and social strategies, the higher proficient he or she would be in spoken English.

The second study is to explore the differences in the choice and use of learning strategies between high-proficient and low-proficient English speakers. Two groups of sixty subjects were selected based on their spoken English proficiency, with thirty being high proficient speakers (score $\geq 78.5$ ) and another thirty being low-proficient speakers (score $\leq 57.0)$. Independent Samples T-test was adopted to analyze the differences made by spoken English proficiency in the choice and use of language learning strategies. The analysis shows that the means of each strategies adopted by high proficient subjects are higher than those by low proficient ones in terms of spoken English. This means that higher proficient English speakers use more language learning strategies than lower proficient speakers. Among six language learning strategies, compensation strategies $($ sig. $=0.005)$, affective strategies $($ sig. $=0.003)$ and social strategies $(\mathrm{sig} .=0.002)$ significantly make differences between high- and low-proficient English speakers. Cognitive strategies (sig. $=0.021)$ and metacognitive strategies $($ sig. $=0.018)$ exert some differences and memory strategies (sig. $=0.031)$ does not contribute any differences. The result means that the more proficient a student gets in spoken English, the more likely he or she would adopt compensation, affective, social, cognitive and metacognitive strategies. As a result, a conclusion can be reached at that not only the choice and use of language learning strategies can make differences in students' spoken English proficiency, but also the performance of the students in the spoken English proficiency test could in return reflect the choice and use of language learning strategies.

\section{CONCLUSIONS OF THE STUDY}

\section{A. Summary of the Study}

The present study reaches some conclusions about the inter-relationship between perceptual learning styles, learning strategies and learners' spoken English proficiency: Firstly, tactile is the most preferred perceptual learning styles and the least preferred one is group style. The order of perceptual learning styles from the most preferred to the least preferred is tactile, kinesthetic, auditory, visual, individual and group styles. Secondly, there are relationships between perceptual learning styles and language learning strategies. Learning styles directly affect the choice and use of learning strategies. Thirdly, most perceptual learning styles bear no relationship with spoken English proficiency except group styles and individual styles. Fourthly, most learning strategies directly and strongly make differences in learners' spoken English proficiency except memory strategy.

\section{B. Suggestions for the Improvement of non-English Spoken English Proficiency}

Some findings are produced from the analysis. Firstly, the students' learning strategy use level is very low, needing improving. Second, students' learning styles need modifying in terms of their spoken English proficiency. Thirdly, the development of students' learning strategies is unbalanced, their use of learning strategies has to be changed. Fourthly, as is discussed, learning styles significantly correlate with learning strategies and learning strategies significantly correlate with students' spoken English proficiency, thus when English teachers work hard on developing students' use of learning strategies, learning styles should not be unnoticed. Based on these findings, the present study tentatively puts forward some suggestions.

\section{Identifying the Situation of Students' Perceptual} Learning Styles and Language Learning Strategies

Reference [3] stated, when commenting on the importance of learning strategies, that "strategies are tools for an active, self-directed involvement, which is essential for developing communicative competence. Appropriate language learning strategies result in improved proficiency and greater self-confidence". Reference [6] also pointed out: "the instructor can...guide students in finding even more effective strategies that are compatible with their own learning style". Both the two scholars emphasized the importance of learning strategies and learning styles in students' learning, and the importance of the teachers in helping students cultivating learning styles and learning strategies. Thus, the significance of identification of students' learning styles and learning strategies is self-evident. By understanding students' learning style preferences and adoptions of learning strategies, teachers could know, in terms of spoken English, which group of students would be more successful and which group of students are bound to more difficulties. Then the teacher can take some steps to modify their learning style preferences and learning strategies accordingly to facilitate students' spoken English proficiency development.

\section{Harmonizing Perceptual Learning Styles and Learning Strategies}

The findings of the paper show us that perceptual learning styles significantly correlate with language learning strategies. But a lot of students do not realize their own preference of learning styles, even those who know something about them do not develop accordingly the strategies that match their learning style preferences. The mismatched relationships between learning styles and learning strategies have to be remedied to contribute to the students' language learning. English teachers should design certain activities to harmonize learning styles and learning strategies.

\section{Widening Students Learning Styles and Learning} Strategies

Based on the findings of the study, non-English major students' utilization of learning strategies are very low, especially compensation and social strategies, so students' learning strategies need to be widened. It is also true of learning styles, although students' learning styles are less malleable than strategies, they can be trained to use other strategies which they do not prefer by heightening their awareness of the advantages and disadvantages of different type of strategies. Therefore, it is essential for teachers to monitor students' learning strategy use and help them understand advantages and disadvantages of their learning styles and strategy use preferences. Meanwhile, teachers should encourage students to master other effective 
strategies apart from their own strategy preferences to improve their spoken English proficiency.

\section{Strengthening Students' Social and Compensation} Strategies

According to the analysis of relationships between learning strategies and spoken English proficiency, social, compensation and affective strategies most significantly correlate with spoken English proficiency. But according to the frequency of learning strategies in the present study social and compensation strategies occupy the least favored learning strategies while affective rank as the second preferred one. Therefore, social and compensation strategies badly need to be enhanced.

\section{REFERENCES}

[1] Ellis, R. The Study of Second Language Acquisition. Oxford: Oxford University Press. 1994.

[2] Reid, J. Perceptual Learning Styles Preference Questionnaire. In: Reid, J (eds.). 1995. Learning Styles in the ESL/EFL Classroom [C]. Boston: Heinle \& Heinle Publishers. 1984.

[3] Oxford, R. L. Language Learning Strategies: What Every Teacher Should Know. New York: Newbury House/Harper and Row. 1990.

[4] Oxford, R. \& Nyikos, M. 1989. Variables affecting choice of language learning strategies by university students. Modern Language Journal. 73/2:291-300

[5] Oxford, R. Use of language learning strategies: a synthesis of studies with implications for teacher training [J]. System 1989,17:235-247.

[6] Rossi-Le, L. Learning styles and strategies in adult immigrant ESL students [A]. In: Reid, J (eds.). Learning Styles in the ESL/EFL Classroom [C], Boston: Heinle \& Heinle Publishers. 1995.

[7] Reid, J. M. The learning style preferences of ESL students. TESOL Quarterly 1987, 21(1):88-112 